\title{
Effect of Kelulut honey supplementation on bone health in male rats on high-carbohydrate high-fat diet
}

\author{
Sophia Ogechi Ekeuku1, Kok-Yong Chin ${ }^{1,2}$, Nur Zuliani Ramli ${ }^{3,4}$, Khairul Anwar \\ Zarkasi $^{4,5}$, Fairus Ahmad ${ }^{3 *}$ \\ ${ }^{1}$ Department of Pharmacology, Faculty of Medicine, Universiti Kebangsaan Malaysia, Kuala Lumpur, Malaysia, ${ }^{2}$ State Key \\ Laboratory of Oncogenes and Related Genes, Renji-Med X Clinical Stem Cell Research Center, Department of Urology, Ren Ji \\ Hospital, School of Medicine, Shanghai Jiao Tong University, Shanghai, China, ${ }^{3}$ Department of Anatomy, Faculty of Medicine, \\ Universiti Kebangsaan Malaysia, Kuala Lumpur, ${ }^{4}$ Department of Biomedical Sciences and Therapeutics, Faculty of Medicine \\ and Health Sciences, Universiti Malaysia Sabah, Kota Kinabalu, ${ }^{5}$ Department of Biochemistry, Faculty of Medicine, Universiti \\ Kebangsaan Malaysia, Kuala Lumpur, Malaysia
}

*For correspondence: Email: fairusahmad@ukm.edu.my; Tel: +603-9145 8632

Sent for review: 8 February 2021

Revised accepted: 25 May 2021

\begin{abstract}
Purpose: To determine the effects of Kelulut honey $(\mathrm{KH})$ on the bone health of rats with metabolic syndrome.

Methods: Male Wistar rats were randomised into normal control and metabolic syndrome $s$ fed with a diet enriched with carbohydrate and fat. The rats in the metabolic syndrome arm were further assigned into the negative control group and honey group supplemented orally with Kelulut honey $(1 \mathrm{~g} / \mathrm{kg})$ daily for eight weeks. After the rats were sacrificed, the trabecular and cortical micro-architecture of the harvested femur was analysed using X-ray micro-computed tomography, while histomorphometric method was used to determine bone cell indices. Femoral biomechanical properties were analysed using a universal mechanical tester.

Results: Total cross-sectional area, osteoid surface and volume, displacement and strain reduced significantly, while eroded surface increased significantly in the rats with metabolic syndrome than the normal rats $(p<0.05)$. The honey group showed a significant reduction in osteoclast surface than the normal healthy control $(p<0.05)$. Other skeletal parameters did not show a significant intergroup difference.

Conclusion: Metabolic syndrome is harmful to bone health and honey has limited effects in reversing these negative effects.
\end{abstract}

Keywords: Calcium, metabolic syndrome, Osteopenia, Osteoporosis, Bone health

\begin{abstract}
This is an Open Access article that uses a fund-ing model which does not charge readers or their institutions for access and distributed under the terms of the Creative Commons Attribution License (http://creativecommons.org/licenses/by/4.0) and the Budapest Open Access Initiative (http://www.budapestopenaccessinitiative.org/read), which permit unrestricted use, distribution, and reproduction in any medium, provided the original work is properly credited.

Tropical Journal of Pharmaceutical Research is indexed by Science Citation Index (SciSearch), Scopus, International Pharmaceutical Abstract, Chemical Abstracts, Embase, Index Copernicus, EBSCO, African Index Medicus, JournalSeek, Journal Citation Reports/Science Edition, Directory of Open Access Journals (DOAJ), African Journal Online, Bioline International, Open-J-Gate and Pharmacy Abstracts
\end{abstract}

\section{INTRODUCTION}

Metabolic syndrome (MetS), which consists of a group of metabolic conditions, escalates individual risk for cardiovascular diseases and diabetes. Hyperglycaemia (elevated triglycerides and reduced high-density lipoprotein cholesterol), central obesity, dyslipidaemia, hypertension and are among the components of MetS [1]. A systematic review in 2017 estimated that the 
adult population affected by MetS globally ranges from 20 to $25 \%$ [2]. MetS may invoke metabolic complications on skeletal health through chronic inflammation and oxidative stress, increase osteoclast formation and bone resorption activities, promote differentiation of mesenchymal stem cells to adipocytes instead of osteogenic progenitors, and increase calcium excretion [3]. Although the overall influence of MetS on the skeletal system is debatable, many studies feeding high-carbohydrate high-fat (HCHF) diet in rats have suggested that it harms bone health through deterioration of bone microarchitecture and mechanical strength $[4,5]$.

Honey is a healthy food made by the Apis genus of bumblebees. It contains various micronutrients, enzymes, polyphenols, vitamins and trace elements [6]. Kelulut honey $(\mathrm{KH})$, produced by stingless bumblebees, is found in Malaysia. It contains phenolic acids, such as 4hydroxyphenyl acetic acid, caffeic acid derivatives, coumaric acid, and gluconic acid [7]. Ramli et al established that $\mathrm{KH}$ reduced body fat percentage by causing adipocyte hypertrophy, blood pressure and serum triglyceride level in rats fed with HCHF diet [7].

Many preclinical studies have reported the skeletal-beneficial effects of honey. Tualang honey, a type of tropical honey in Malaysia, was found to prevent deterioration of skeletal microarchitecture in ovariectomised rats $[8,9]$. The bone-protective properties of honey are attributed to the presence of antioxidants and polyphenols [10]. Polyphenols enhance bone formation by promoting the differentiation of mesenchymal stem cells to osteoblast progenitors and influencing signal transduction pathways in bone cells, such as Wnt, bone morphogenic protein, forkhead box protein O3, runt-related transcription factor 2 and osterix, that promote bone formation [11,12]. Quercetin and kaempferol, commonly found in honey, enhance osteoclast apoptosis, thereby inhibiting bone loss [13]. Kaempferol also prevented castrationinduced bone resorption by promoting osteoblast function [14]. However, there are limited studies on the influence of $\mathrm{KH}$ on skeletal health currently.

The current study examined the actions of $\mathrm{KH}$ on skeletal health defined by femoral microarchitecture, biomechanical strength, and histomorphometry in rats with MetS induced by the HCHF diet. $\mathrm{KH}$ supplementation was hypothesised to reverse the adverse effects of MetS on the skeletal system. The results of the phytochemical analysis of $\mathrm{KH}$ and the metabolic outcomes of MetS-supplemented rats have been published elsewhere [7], so they were not included in this paper.

\section{EXPERIMENTAL}

\section{Preparation of $\mathrm{KH}$}

A local honeybee farm in Gombak, Selangor, Malaysia, provided unprocessed $\mathrm{KH}$ obtained from Heterotrigona itama (stingless honey bees). The honey was kept at $4^{\circ} \mathrm{C}$ in a glass jar before use. $\mathrm{KH}$ was mixed with purified; water (ratio of 1:1) for oral administration.

\section{HCHF preparation}

The composition of HCHF diet given to the rats is presented in Table 1. Fructose powder (Merck, New Jersey, USA) (25 mg/100 mL) was added into the drinking water of the HCHF group. Access of rats to food and water was not limited.

Table 1: Composition of HCHF diet

\begin{tabular}{|c|c|c|}
\hline Ingredient & Manufacturer & Weight \\
\hline $\begin{array}{r}\text { D-(-)-Fructose } \\
\text { Emprove }^{\circledR}\end{array}$ & $\begin{array}{c}\text { Merck, Darmstadt, } \\
\text { USA }\end{array}$ & $175 \mathrm{~g}$ \\
\hline $\begin{array}{r}\text { Sweetened } \\
\text { condensed milk }\end{array}$ & $\begin{array}{l}\text { Fraser \& Neave } \\
\text { Holdings Bhd., Kuala } \\
\text { Lumpur, Malaysia }\end{array}$ & $395 \mathrm{~g}$ \\
\hline $\begin{array}{r}\text { Enrico's Pure } \\
\text { Ghee }\end{array}$ & $\begin{array}{l}\text { Raviraj Sdn. Bhd., } \\
\text { Penang, Malaysia }\end{array}$ & $200 \mathrm{~g}$ \\
\hline $\begin{array}{r}\text { Hubble, Mendel } \\
\text { and Wakeman } \\
\text { salt mixture }\end{array}$ & $\begin{array}{l}\text { MP Biomedicals, } \\
\text { California, USA }\end{array}$ & $25 \mathrm{~g}$ \\
\hline $\begin{array}{r}\text { Powdered rat } \\
\text { chow }\end{array}$ & $\begin{array}{l}\text { Gold Coin Feedmills } \\
\text { (M) Sdn. Bhd., } \\
\text { Selangor, Malaysia }\end{array}$ & $155 \mathrm{~g}$ \\
\hline Tap water & - & $\begin{array}{c}50 \mathrm{~g} / \mathrm{kg} \\
\text { diet }\end{array}$ \\
\hline
\end{tabular}

\section{Animals}

The Laboratory Animal Resource Unit, Universiti Kebangsaan Malaysia, provided the 24 male Wistar rats (250 - $300 \mathrm{~g}$; three months old) used in this study. Before being used, the rats were acclimatised to the housing facilities for two weeks. The rats dwelt individually in ventilated plastic cages at the Animal Laboratory of the Anatomy Department, Universiti Kebangsaan Malaysia (Cheras, Malaysia), at an ambient temperature of $25 \pm 3{ }^{\circ} \mathrm{C}$ and 12-h light/dark cycle throughout the study. This study followed the guidelines of the Institute for Laboratory Animal Research, National Research Council, Guide for the Care and Use of Laboratory Animals (1996) [15]. The Animal Ethics Committee at Universiti Kebangsaan Malaysia reviewed and approved the study procedures (approval code: ANAT/PP/2017/FAIRUS AHMAD/27-SEPT./871-OCT.-2017-SEPT.-2018). 


\section{Study design}

The rats were group equally into the normal control, negative control (on HCHF diet), and honey group $(n=8)$ (on HCHF diet and honey supplementation). Standard rat chow and tap water were given to the rats in the normal control group. For 16 weeks, the negative control and honey groups were given an HCHF diet with fructose-enriched drinking water $(25 \mathrm{mg} / 100 \mathrm{~mL})$. From Week 8 to the end of the experiment, the honey group was orally administered $1 \mathrm{~g} / \mathrm{kg}$ of $\mathrm{KH}$ daily. After 16 weeks, rats were euthanised with ketamine/xylazine/zoletil (KTX) mix and left, and right femurs were harvested and cleaned. Neutral buffered formalin was used to preserve right femurs, while the left femurs were kept at $80^{\circ} \mathrm{C}$.

\section{Micro-computed tomography}

A micro-CT device was used to determine microarchitectural parameters of the bone (cortical and trabecular bone parameters) (Skyscan 1076 scanner, Scanco Medical, Switzerland). The left femur was placed in the sample holder before scanning, and the following settings were used: X-ray voltage of $70 \mathrm{kV}, \mathrm{X}$-ray current of $100 \mu \mathrm{A}$, $0.5 \mathrm{~mm}$ aluminium filter, $0.7^{\circ}$ rotation step, image pixel size of $9 \mu \mathrm{m}$, medium camera resolution, and frame averaging of 3 . The integration time was set to 200 milliseconds. The software NRecon was used to reconstruct the slides (V1.6.10.4, Skyscan, Belgium). The trabecular volume of interest (VOI) began at $1.0 \mathrm{~mm}$, while the cortical VOI began at $5.0 \mathrm{~mm}$ from the proximal growth plate and extended to the tibial distal end. CTAn software (V1.16.1.0 +, SkyScan, Belgium) was used to assess the images.

\section{Histomorphological examination of femur}

The decalcified femurs were used for the histomorphometric analysis. The right femurs were soaked in $10 \%$ neutral buffered formalin for two days before being sawed into halves and subjected to 30 -day decalcification in $10 \%$ ethylenediaminetetraacetic acid (EDTA). The EDTA solution was replaced three times per week. Decalcified bone samples were placed in a plastic cassette and soaked in tap water overnight before being dehydrated for 9 hours with a graded alcohol series. The dehydrated bone samples were soaked in absolute toluene overnight after 90 minutes in an alcohol and toluene $(1: 1)$ solution.

Embedding of samples in paraffin wax at $60^{\circ} \mathrm{C}$ was then performed. Using a microtome (Leica
RM2235, Nussloch, Germany), $5 \mu$ m-thick paraffin sections were produced, placed on glass slides, cleared with xylene and rehydrated with decreasing alcohol concentrations and finally rinsed with water. Haematoxylin and eosin (H\&E) stain was used to colour the slides, which were then dehydrated with increasing alcohol concentrations, and mounted with mounting media and coverslips. The slides were examined under a light microscope (Zeiss Primo Star, Germany), and images were captured at 400 magnification using the Zen 2.6 lite software. The Weibel grid technique was used to quantify bone cellular indices.

\section{Femur three-point bend testing and analysis biomechanical testing}

The mid-point of femoral diaphysis was put through the three-point bending test to estimate the skeletal mechanical properties. The femurs were thawed at room temperature before their weight, length and width were measured. Each bone was loaded from above at the mid-point on its anterior surface between two lower supports $10 \mathrm{~mm}$ apart. The bones were fractured by a Shimadzu Universal Testing Machine (Autograph AGS-X 500N, Japan) that applied force at a speed of $5 \mathrm{~mm} / \mathrm{min}$ onto the bone surface. Trapezium $X$ software analysed the input from the machine and generated the biomechanical parameters.

\section{Statistical analysis}

Statistical analysis was performed using the statistical package for social sciences (SPSS) version 26 (IBM, Armonk, NY, USA). The intergroup differences of bone microarchitectural and biomechanical parameters were determined using one-way analysis of variance with Tukey HSD. All data were presented in mean \pm standard error. Statistical significance was set at $p<0.05$.

\section{RESULTS}

\section{Micro-architectural indices of rats}

Total cross-sectional area (Tt.Ar) was significantly decreased in the negative control group compared to the normal control $(p<0.05)$. Tt.Ar of the honey supplemented group was not different statistically from the normal control and negative control $(p<0.05)$. The differences in other cortical bone parameters among the experimental groups were not significant statistically $(p>0.05)$. All trabecular parameters did not differ significantly among the experimental groups $(p>0.05)$. (Table 2). Figure 
1 shows three-dimensional images of the microstructure of the bone. No apparent difference in the trabecular and cortical bone structure among the groups could be observed.

\section{Biomechanical characteristics}

Displacement and strain were significantly reduced in the negative control group than the normal control group $(p<0.05)$. However, the displacement and strain of the honey supplemented group were not significantly different with the normal control and positive control groups $(p>0.05)$. All study groups showed no significant differences in load, stress, stiffness and Young's modulus of elasticity ( $p>$ 0.05). (Table 3).

\section{Histomorphology of the femur}

Figure 2 shows H\&E-stained photomicrographs. Compared to the normal control group, ES/BS was significantly increased while OS/BS and
OV/BV were significantly reduced in the negative control group $(p<0.05)$.

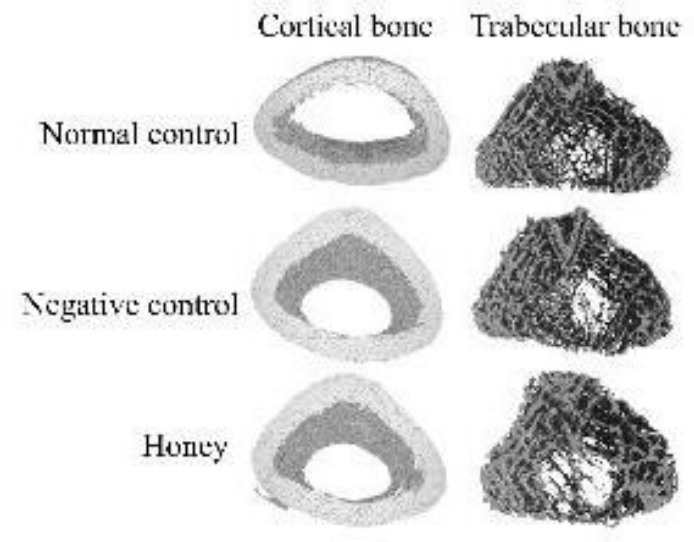

Figure 1: 3D images of trabecular and cortical bone obtained from micro-CT scanning in the normal control, negative control and Kelulut honey-treated rats at the conclusion of the experiment

Table 2: Microstructural indices of the rats subjected to different treatment

\begin{tabular}{|c|c|c|c|c|}
\hline Microstructure index & Abbreviation & $\begin{array}{l}\text { Normal } \\
\text { control }\end{array}$ & Negative control & Honey \\
\hline \multicolumn{5}{|l|}{ Trabecular bone } \\
\hline Trabecular Thickness (mm) & Tb.Th & $0.0579 \pm 0.008$ & $0.0408 \pm 0.006$ & $0.0483 \pm 0.003$ \\
\hline Trabecular Seperation (mm) & Tb.Sp & $0.238 \pm 0.060$ & $0.106 \pm 0.020$ & $0.162 \pm 0.041$ \\
\hline Trabecular Number (1/mm) & Tb.N & $4.04 \pm 0.58$ & $3.85 \pm 0.70$ & $4.50 \pm 0.38$ \\
\hline Bone Volume Fraction (\%) & $\mathrm{BV} / \mathrm{TV}$ & $21.2 \pm 1.8$ & $17.7 \pm 3.0$ & $21.1 \pm 1.1$ \\
\hline Connectivity Density $\left(1 / \mathrm{mm}^{3}\right)$ & Conn.D & $2953 \pm 759$ & $3288 \pm 659$ & $3356 \pm 455$ \\
\hline Structural Model Index & SMI & $1.63 \pm 0.25$ & $1.82 \pm 0.27$ & $1.62 \pm 1.31$ \\
\hline \multicolumn{5}{|l|}{ Cortical bone } \\
\hline Total Cross-sectional Area $\left(\mathrm{mm}^{2}\right)$ & Tt.Ar & $13.8 \pm 1.1$ & $9.18 \pm 1.42^{*}$ & $10.4 \pm 0.5$ \\
\hline Cortical Area $\left(\mathrm{mm}^{2}\right)$ & Ct.Ar & $2.97 \pm 0.29$ & $2.00 \pm 0.39$ & $2.31 \pm 0.18$ \\
\hline Cortical Area Fraction (\%) & Ct.Ar/Tt.Ar & $21.6 \pm 2.0$ & $18.7 \pm 3.2$ & $22.1 \pm 1.1$ \\
\hline Cortical Thickness (mm) & Cr.Th & $0.219 \pm 0.077$ & $0.0618 \pm 0.009$ & $0.0634 \pm 0.005$ \\
\hline
\end{tabular}

Table 3: Femoral biomechanical strength of the rats subjected to different treatment

\begin{tabular}{lccc}
\hline Parameter & Normal control & Negative control & Honey \\
\hline Femur length $(\mathrm{mm})$ & $39.1 \pm 0.7$ & $32.2 \pm 4.6$ & $36.2 \pm 0.6$ \\
Femur width $(\mathrm{mm})$ & $4.63 \pm 0.11$ & $3.82 \pm 0.55$ & $4.43 \pm 0.12$ \\
Femur weight $(\mathrm{g})$ & $0.863 \pm 0.078$ & $0.538 \pm 0.129$ & $0.825 \pm 0.073$ \\
Load $(\mathrm{N})$ & $116 \pm 12.1$ & $81.0 \pm 16.1$ & $93.5 \pm 8.0$ \\
Displacement $(\mathrm{mm})$ & $5.20 \pm 0.23$ & $3.15 \pm 0.63^{* *}$ & $4.36 \pm 0.25$ \\
Stiffness (N/mm) & $22.5 \pm 2.4$ & $23.7 \pm 4.8$ & $21.4 \pm 1.2$ \\
Stress (Nmm-2) & $631 \pm 66$ & $465 \pm 93$ & $524 \pm 36$ \\
Strain (\%) & $5.27 \pm 0.23$ & $3.23 \pm 0.67^{* *}$ & $4.27 \pm 0.22$ \\
Young's Modulus of elasticity & $119 \pm 13$ & $134 \pm 27$ & $123 \pm 7$ \\
\hline
\end{tabular}

The mean \pm standard error of the mean ( $n=8$ rats in each group) is used to express the results. One-way analysis of variance (ANOVA) with Tukey HSD pairwise comparison was used to determine statistical significance; ${ }^{* *} p<0.01$ vs normal control group 
Table 4: Static bone histomorphometric parameters

\begin{tabular}{lcccc}
\hline Bone static index & Abbreviation & $\begin{array}{c}\text { Normal } \\
\text { control }\end{array}$ & Negative control & Honey \\
\hline Osteoblast surface/bone surface (\%) & Ob.S/BS & $0.119 \pm 0.042$ & $0.026 \pm 0.013$ & $0.039 \pm 0.021$ \\
Osteoclast surface / bone surface (\%) & Oc.S/BS & $0.110 \pm 0.028$ & $0.076 \pm 0.022$ & $0.012 \pm 0.012^{* *}$ \\
Eroded surface/bone surface (\%) & ES/BS & $0.206 \pm 0.047$ & $0.404 \pm 0.041^{*}$ & $0.331 \pm 0.057$ \\
Osteoid surface/bone surface (\%) & OS/BS & $0.498 \pm 0.059$ & $0.078 \pm 0.022^{* * *}$ & $0.272 \pm 0.077^{*}$ \\
Osteoid volume/bone volume (\%) & OV/BV & $0.192 \pm 0.035$ & $0.050 \pm 0.026^{*}$ & $0.112 \pm 0.034$ \\
\hline
\end{tabular}

The mean \pm standard error of the mean is used to express the data ( $n=8 /$ group). One-way analysis of variance with Tukey HSD pairwise comparison was used to determine statistical significance. ${ }^{*} p<0.05,{ }^{* *} p<0.01$, ${ }^{* * * *} p<$ 0.001 vs. control group

Oc.S/BS and OS/BS were significantly reduced in the honey group $(p<0.05)$ than the normal control group. Across all treatment groups, the Ob.S/BS was similar $(p>0.05)$. (Table 4).

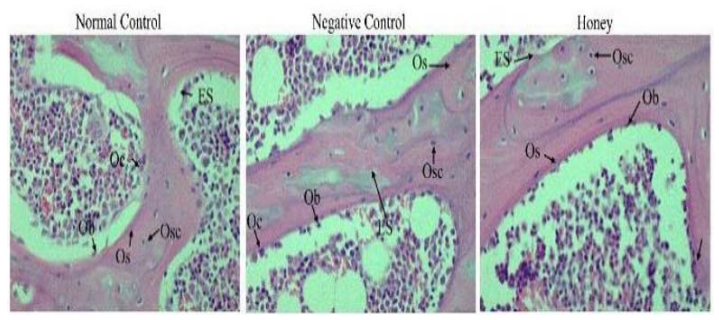

Figure 2: Representative micrographs of decalcified trabecular bone stained with haematoxylin and eosin from the normal control, negative control, and honeytreated groups (X400 magnification). Abbreviations: ES, eroded surface; Ob, osteoblast; Oc, osteoclast; Os, osteoid; Osc, osteocyte

\section{DISCUSSION}

This study showed marginal deterioration of bone health induced by MetS, as evidenced by significant reduction in Tt.Ar, OS/BS, OV/BV, displacement and strain in the negative control group compared to the normal control group. The ES/BS also increased in the negative control group in comparison to normal control group. Other microstructural and biomechanical parameters were comparable in rats receiving standard diet and $\mathrm{HCHF}$ diet. $\mathrm{KH}$ supplementation increased OS/BS and reduced Oc.S/BS in rats fed with HCHF. However, it did not reverse other bone-damaging impacts of $\mathrm{HCHF}$ diet.

Micro-computed tomography provides a highresolution, three-dimensional view of trabecular and cortical bone structure. This technique serves as a benchmark for skeletal geometry evaluation [16]. The minimum parameters required to describe trabecular bone microarchitecture are BV/TV, Tb.N, Tb.Th, and Tb.Sp, whereas the minimum parameters to describe cortical bone micro-architecture are Tt.Ar, Ct.Ar,
Ct.Ar/Tt.Ar, and Ct.Th [17]. The microarchitecture of trabecular and cortical bone is critical in determining bone quality and strength [18].

Only Tt.Ar deteriorated in rats fed an HCHF diet in this study, while the other micro-architecture parameters were unaffected. This finding contradicts that of a previous study. Wong et al [4] reported a significant deterioration of trabecular microstructure, Ct.Ar and Tt.Ar, in rats receiving $\mathrm{HCHF}$ diet of similar composition in our study after 20 weeks. Since the rats in the present study were given HCHF diet for 16 weeks only, the negative effects might be attenuated. In another study, male Sprague Dawley rats fed with a high-fat diet (HFD) for 22 weeks showed significant deterioration of trabecular bone. Expression of osteoblast markers such as alkaline phosphatase and total procollagen type $1 \mathrm{~N}$-terminal propeptide was reduced, but osteoclast bone resorption marker, i.e. C-terminal telopeptide, decreased in HDF-fed rats [19]. In the study by Lac et al [20], male Wistar rats fed with HFD for 10 weeks showed a significant reduction in bone mineral density, bone mineral content and skeleton. In contrast, Yanagihara et al [21] reported increased bone mineral density in female Wistar rats fed with HFD for 5 weeks. However, there were no corresponding changes in microstructural and mechanical bone properties in these rats.

In this study, $\mathrm{KH}$ did not reverse the deterioration of Tt.Ar caused by HCHF diet. It also did not alter other trabecular and cortical microstructural indices in the rats. This observation contradicted previous studies. In a study by Zaid et al [9], ovariectomised (OVX) female rats treated with $200 \mathrm{mg} / \mathrm{kg}$ of Tualang honey for 6 weeks showed a significant increase in trabecular microstructure than the OVX control group. Kamaruzzaman et al [22] demonstrated that male rats with bone loss induced by glucocorticoids treated with $0.2 \mathrm{~g} / \mathrm{kg}$ of $\mathrm{KH}$ for eight weeks exhibited a substantial increase in trabecular bone microstructure than the negative control group. Since the rats in this 
study did not suffer substantial bone microstructure loss due to $\mathrm{HCHF}$ diet, we conclude that $\mathrm{KH}$ did not improve skeletal microstructure in rats without prior bone damage.

Biomechanical properties of bone can be classified into extrinsic properties (load, stiffness and displacement) and intrinsic properties (stress, strain and Young's modulus of elasticity). The extrinsic properties are influenced by the density, architecture and tissue properties of the bone, while the intrinsic parameters are independent of the amount of bone in the tissue [23]. Load and stress measure the maximum force needed to create bone fracture (bone strength). Stiffness and Young's modulus of elasticity show the resistance of the bone against elastic deformation. Displacement and strain measure the ability of the bone to undergo significant deformation before fracture (ductility) [23]. In this study, rats receiving HCHF showed reduced ductility indicated by reduced displacement and strain than the normal control group. Wong et al [5] reported that male rats given HCHF diet for 20 weeks showed decreased load but increased displacement and strain. Therefore, prolonged consumption of $\mathrm{HCHF}$ diet may reduce bone strength.

In this study, $\mathrm{KH}$ supplementation did not enhance bone strength in rats fed with $\mathrm{HCHF}$ diet. This result contradicted previous studies, which found that honey supplementation increased bone strength. According to Yudaniayanti et al [24], 3-month-old OVX female rats supplemented with honey $(100,200$ and 400 $\mathrm{mg} / \mathrm{kg}$ ) for 12 weeks showed increased bone strength. Several studies have also reported that honey supplementation $(100 \mathrm{mg} / \mathrm{kg})$ in female Sprague Dawley rats ( 8 and 16 weeks) increased trabecular bone micro-architecture and biomechanical properties [25-27].

Static bone histomorphometric parameters provide a snapshot of bone remodelling activity by clarifying the quantity of unmineralised bone (osteoid) and degree of resorption cavities in the trabecular bone [28]. In this study, rats with MetS showed a significant decrease in OV/BV and OS/BS, and a significant increase in ES/BS. These observations were comparable to a previous study by Wong et al [4]. The significant reduction in OS/BS and OV/BV suggests that $\mathrm{HCHF}$ reduced bone formation. The increase in ES/BS signifies that the HCHF diet increased bone resorption. This study suggests that 16 weeks of HCHF diet is enough to impair bone formation. Wang et al [29] showed decreased osteoblast differentiation in mesenchymal stem cells exposed to high glucose level.
In this study, $\mathrm{KH}$ group showed decreased OS/BS and Oc.S/BS than the normal control group. In contrast, Kamaruzzaman et al [22] showed that male rats with glucocorticoidinduced bone loss and treated with $0.2 \mathrm{~g} / \mathrm{kg}$ of $\mathrm{KH}$ for eight weeks experienced an increase in Ob.S/BS and a reduction in Oc.S/BS than the negative control group. These findings suggest that while $\mathrm{KH}$ did not improve bone formation, it did reduce the number of osteoclasts. However, it will take more time for these cellular changes to affect the bone structure.

Several studies have explored the impact of MetS on skeletal health. Obesity protects the skeleton via increased mechanical loading on the bone. Adipose tissue also secretes hormones that stimulate bone formation, such as oestradiol, insulin, amylin and preptin. On the other hand, increased adipocyte differentiation hinders osteoblast differentiation in the bone marrow because they originate from the same progenitor (mesenchymal stem cell) [30]. Pro-inflammatory cytokines also originate from adipose tissue. They could upregulate receptor activator of NFKB (RANK)/RANK ligand pathway, leading to osteoclast differentiation [31]. Excess urinary calcium secretion leads to secondary parathyroidism in hypertensive conditions, which can accelerate osteoporosis by increasing calcium mobilisation from the bone [32]. Hyperglycemia promotes the production of reactive oxygen species, which enhances osteoclastogenesis and bone resorption activity, and subsequently, bone loss [33]. All these mechanisms could have contributed to the deterioration of bone health of rats receiving the $\mathrm{HCHF}$ diet, but $\mathrm{KH}$ did not reverse the skeletal adverse effects.

Several limitations of this study need to be addressed. The primary aim of this research was to determine the effects of $\mathrm{KH}$ in reversing MetS and these findings have already been published [7]. The dose and treatment period might not be optimal to produce significant skeletal effects, considering that it takes more time for cellular changes to be reflected on bone structure. In future studies, the dose and duration of $\mathrm{KH}$ treatment could be increased and longitudinal follow-up of the skeletal parameters could be performed to address this limitation. The molecular response of the bone towards $\mathrm{KH}$ supplementation was also not examined in this study. HCHF diet is known to induce inflammation in rats, which could potentially exert negative effects on the skeletal system [4]. As a result, future research should include relevant markers to study the influence of MetS inflammation on skeletal health. 


\section{CONCLUSION}

MetS reduces bone size and compromises bone strength. Kelulut honey did not reverse HCHF diet-induced bone loss. More comprehensive studies on bone cellular and homoeostasis markers should be performed to validate these findings.

\section{DECLARATIONS}

\section{Acknowledgement}

We thank Universiti Kebangsaan Malaysia for funding the study through Dana Fundamental (grant no. FF-2017-446) and Geran Galakan Penyelidik (no. GGP-2017-056). We appreciate the assistance and support of all technical staff from the Department of Anatomy and Department of Pharmacology, Faculty of Medicine, Universiti Kebangsaan Malaysia.

\section{Conflict of interest}

This work has no potential conflicts of interest.

\section{Contribution of authors}

We declare that this work was completed by the authors named in this article, and that the authors will be held liable for any claims relating to the content of this article. The manuscript was read and approved for publication by all authors. The study was conceived and designed by Fairus Ahmad and Kok-Yong Chin, with data collected and analysed by Nur Zuliani Ramli, Khairul Anwar Zarkasi, and Sophia Ogechi Ekeuku, and the manuscript written by Sophia Ogechi Ekeuku. Kok-Yong Chin and Fairus Ahmad secured funding of the study and provided critical review to the manuscript.

\section{Open Access}

This is an Open Access article that uses a funding model which does not charge readers or their institutions for access and distributed under the terms of the Creative Commons Attribution License (http://creativecommons.org/licenses/by/ 4.0) and the Budapest Open Access Initiative (http://www.budapestopenaccessinitiative.org/rea d), which permit unrestricted use, distribution, and reproduction in any medium, provided the original work is properly credited.

\section{REFERENCES}

1. Wong S, Chin K-Y, Suhaimi F, Ahmad F, Ima-Nirwana S. The Effects of a Modified High-carbohydrate High-fat Diet on Metabolic Syndrome Parameters in Male Rats. Exp Clin Endocrinol Diabetes 2018; 126(04): 205-212.

2. Ranasinghe $P$, Mathangasinghe $Y$, Jayawardena $R$, Hills $A P$, Misra A. Prevalence and trends of metabolic syndrome among adults in the asia-pacific region: a systematic review. BMC Public Health 2017; 17(1): 101.

3. Wong S, Chin K-Y, Suhaimi F, Ahmad F, Ima-Nirwana S. The Relationship between Metabolic Syndrome and Osteoporosis: A Review. Nutrients 2016; 8(6): 347-365.

4. Wong SK, Chin K-Y, Suhaimi FH, Ahmad F, Ima-Nirwana $S$. Effects of metabolic syndrome on bone mineral density, histomorphometry and remodelling markers in male rats. Bader M, editor. PLoS One 2018; 13(2): e0192416.

5. Wong SK, Chin K-Y, Suhaimi FH, Ahmad F, Jamil NA, Ima-Nirwana S. Osteoporosis is associated with metabolic syndrome induced by high-carbohydrate highfat diet in a rat model. Biomed Pharmacother 2018; 98 : 191-200.

6. Pasupuleti VR, Sammugam L, Ramesh N, Gan SH. Honey, Propolis, and Royal Jelly: A Comprehensive Review of Their Biological Actions and Health Benefits. Oxid Med Cell Longev 2017; 2017: 1-21.

7. Ramli NZ, Chin K-Y, Zarkasi KA, Ahmad F. The Beneficial Effects of Stingless Bee Honey from Heterotrigona itama against Metabolic Changes in Rats Fed with High-Carbohydrate and High-Fat Diet. Int J Environ Res Public Health 2019;16(24): 4987-5003.

8. Yudaniayanti IS, Primarizky $H$, Nangoi L, Yuliani GA. Protective effects of honey by bees (Apis dorsata) on decreased cortical thickness and bone impact strength of ovariohysterectomised rats as models for menopause. Vet world 2019; 12(6): 868-876.

9. Zaid SSM, Sulaiman SA, Othman NH, Soelaiman I-N, Shuid AN, Mohamad N, Muhamad N. Protective effects of Tualang honey on bone structure in experimental postmenopausal rats. Clinics (Sao Paulo) 2012; 67(7): 779-784.

10. Gheldof N, Wang X-H, Engeseth NJ. Buckwheat honey increases serum antioxidant capacity in humans. J Agric Food Chem. 2003; 51(5): 1500-1505.

11. Chen J-R, Lazarenko OP, Wu X, Kang J, Blackburn ML, Shankar K, Badger TM, Ronis MJJ. Dietary-induced serum phenolic acids promote bone growth via p38 $M A P K / \beta$-catenin canonical Wnt signaling. J Bone Miner Res 2010; 25(11): 2399-2411.

12. Guo AJY, Choi RCY, Cheung AWH, Chen VP, Xu SL, Dong TTX, Chen JJ, Tsim KWK. Baicalin, a flavone, induces the differentiation of cultured osteoblasts: an action via the Wnt/beta-catenin signaling pathway. J Biol Chem 2011; 286(32): 27882-27893.

13. Wattel A, Kamel S, Mentaverri R, Lorget F, Prouillet $C$, Petit J-P, Fardelonne P, Brazier M. Potent inhibitory effect of naturally occurring flavonoids quercetin and kaempferol on in vitro osteoclastic bone resorption. Biochem Pharmacol 2003; 65(1): 35-42.

Trop J Pharm Res, June 2021; 20(6): 1191 
14. Trivedi R, Kumar S, Kumar A, Siddiqui JA, Swarnkar G, Gupta V, Kendurker A, Dwivedi AK, Romero JR, Chattopadhyay N. Kaempferol has osteogenic effect in ovariectomised adult Sprague-Dawley rats. Mol Cell Endocrinol 2008; 289(1-2): 85-93.

15. Clark JD, Gebhart GF, Gonder JC, Keeling ME, Kohn DF. The 1996 Guide for the Care and Use of Laboratory Animals. ILAR J 1997; 38(1): 41-48.

16. Bouxsein ML, Boyd SK, Christiansen BA, Guldberg RE, Jepsen KJ, Müller R. Guidelines for assessment of bone microstructure in rodents using micro-computed tomography. J Bone Miner Res 2010; 25(7): 1468-1486.

17. Pirih F, Lu J, Ye F, Bezouglaia O, Atti E, Ascenzi M-G, Tetradis S, Demer L, Aghaloo T, Tintut Y. Adverse effects of hyperlipidemia on bone regeneration and strength. J Bone Miner Res 2012; 27(2): 309-318.

18. Chen F, Wang $Y$, Wang $H$, Dong Z, Wang $Y$, Zhang $M, L i$ J, Shao S, Yu C, Huan Z et al. Flaxseed oil ameliorated high-fat-diet-induced bone loss in rats by promoting osteoblastic function in rat primary osteoblasts. Nutr Metab (Lond) 2019; 16(1): 71-83.

19. Graham LS, Tintut Y, Parhami F, Kitchen CMR, Ivanov $Y$, Tetradis S, Effros RB. Bone density and hyperlipidemia: the T-lymphocyte connection. J Bone Miner Res 2010; 25(11): 2460-2469.

20. Lac G, Cavalie H, Ebal E, Michaux O. Effects of a high fat diet on bone of growing rats. Correlations between visceral fat, adiponectin and bone mass density. Lipids Health Dis 2008; 7(1): 16-19.

21. Yanagihara GR, Shimano RC, Atsuko Tida J, Suzuki Yamanaka J, Yasuyo Fukada S, Issa JPM, Shimano AC, Tavares JMRS. Influence of high-fat diet on bone tissue: An experimental study in growing rats. J Nutr Heal Aging 2017; 21(10): 1337-1343.

22. Kamaruzzaman M, Thanu A, Yusof M, Soelaiman I, Ramli E. Kelulut honey ameliorates glucocorticoid induced osteoporosis via its antioxidant activity in rats. Asian Pac J Trop Biomed 2019; 9(12): 493-500.

23. Forestier-Zhang L, Bishop N. Bone strength in children: understanding basic bone biomechanics. Arch Dis Child - Educ Pract 2016; 101(1): 2-7.
24. Yudaniayanti IS, Primarizky H, Nangoi L. The effects of honey (Apis dorsata) supplements on increased bone strength in ovariectomised rat as animal model of osteoporosis. In: AIP Conference Proceedings. American Institute of Physics 2018: 020004.

25. Mosavat M, Ooi FK, Mohamed M. Effects of honey supplementation combined with different jumping exercise intensities on bone mass, serum bone metabolism markers and gonadotropins in female rats. BMC Complement Altern Med 2014; 14(1): 126.

26. Ooi FK, Tavafzadeh SS, Hung L, Hung W, He Y. Tibial Bone Mineral Density, Geometry, and Mechanical Properties in Response to High-Impact Exercise and Honey Supplementation in Rats. Asian J Exerc Sport Sci 2014; 11(1).

27. Tavafzadeh SS, Ooi FK, Chen CK, Sulaiman SA, Hung LK. Bone Mechanical Properties and Mineral Density in Response to Cessation of Jumping Exercise and Honey Supplementation in Young Female Rats. Van Wijnen A, editor. Biomed Res Int 2015; 2015: 1-8.

28. Kulak CAM, Dempster DW. Bone histomorphometry: a concise review for endocrinologists and clinicians. Arquivos Brasileiros de Endocrinologia \& Metabologia. scielo 2010; 54: 87-98.

29. Wang J, Wang B, Li Y, Wang D, Lingling E, Bai Y, Liu H. High glucose inhibits osteogenic differentiation through the BMP signaling pathway in bone mesenchymal stem cells in mice. EXCLI J 2013; 12: 584-597.

30. Reid IR. Fat and bone. Arch Biochem Biophys 2010; 503(1): 20-27.

31. Calder PC, Ahluwalia N, Brouns F, Buetler T, Clement $K$, Cunningham $K$, Esposito $K$, Jonsson LS, Kolb $\mathrm{H}$, Lansink $M$ et al. Dietary factors and low-grade inflammation in relation to overweight and obesity. $\mathrm{Br} \mathrm{J}$ Nutr 2011; 106 Suppl: S5-78.

32. Nakagami H, Morishita R. [Hypertension and osteoporosis]. Clin Calcium 2013; 23(4): 497-503.

33. García-Hernández A, Arzate H, Gil-Chavarría I, Rojo R, Moreno-Fierros $L$. High glucose concentrations alter the biomineralization process in human osteoblastic cells. Bone 2012; 50(1): 276-288. 